\title{
Accuracy of Student Calibration on Specific Topics: Very Good Students vs. Others
}

\author{
D. Neil Westley \\ Petroleum Institute, Abu Dhabi, UAE
}

nwestley@pi.ac.ae

\begin{abstract}
This study examines the relationship between students overall result in a midterm grade in Excel and their ability to predict how well they will perform on specific topics in three Excel tests. The metacognitive skill of predicting performance on specific topics permits appropriate focus in preparing for tests. The hypothesis is that very good students will have significantly more success calibrating specific topics than average and poor students. The results validate the hypothesis.
\end{abstract}

Keywords: student prediction of performance, mid-eastern, IT, Meta cognition

\section{Introduction}

Two groups of students in studying MS Excel, at the Petroleum Institute in Abu Dhabi are involved in the study. One group studying advanced Excel functions predicted their performance on each topic on two separate tests. The other group studying an elementary course in Excel was asked to predict their performance on each topic in a test a couple of days before. . It is the author's contention that very good students "know what they know" that is, they have metacognitive awareness of their grasp of material, to a significantly greater degree than other students, and will therefore calibrate better than average and poor students.

The students are entirely Middle Eastern young men at university entry level. Most of the students are recent graduates from public high schools in the UAE where they have received instruction in Arabic, but have also studied English for several years, although a few are from other countries in the Middle East. Our course is taught in English therefore they are second language or foreign language learners in the context of this research.

While research has already established such a connection in general terms, i.e. that better students are able to predict their overall result better than poorer students, students ability to predict their performance on specific topics is an important element of their meta-cognition because such knowledge can help them to better focus on their areas of weakness when studying and preparing for tests, that is if students know precisely what information the lack they know what to study.

Material published as part of this publication, either on-line or in print, is copyrighted by the Informing Science Institute. Permission to make digital or paper copy of part or all of these works for personal or classroom use is granted without fee provided that the copies are not made or distributed for profit or commercial advantage AND that copies 1) bear this notice in full and 2) give the full citation on the first page. It is permissible to abstract these works so long as credit is given. To copy in all other cases or to republish or to post on a server or to redistribute to lists requires specific permission and payment of a fee. Contact Publisher@InformingScience.org to request redistribution permission.
This may have implications regarding how their superior meta-cognition is instrumental in producing their superior performance.

\section{Review of the Literature}

Calibration, a particular component of metacognition has been defined by Horgan (1990) as "the accuracy with which 
students can predict their own performance".

Researchers have reported differences in metacognitive abilities between capable and less capable learners (Baker, 1989; Brown \& Campione, 1986; Garner \& Alexander, 1989). According to Everson and Tobias (1998), "In general students with effective metacognitive skills accurately estimate their knowledge in a variety of domans, monitor their on-going learning, update their knowledge, and develop effective plans for new learning" (p. 65).

Calibration accuracy has been linked to both metacognitive skills and to achievement levels (Butler \& Winne, 1995; Nietfeld \& Schraw, 2002; Schraw, Potenza, \& Nebelsick-Gullet, 1993). Further studies report that better students calibrate more effectively than poorer students. (Bol, Hacker, \& Allen, 2005; Horgan, 1990; Kruger \& Dunning, 1999) Kruger and Dunning found considerable overestimation of performance among the bottom quartile of students but very little among the top quartile. Horgan reported that "students who know what they know for a particular exam perform better on that exam" (p. 3).

The obvious advantage to calibration ability as stated by Everson \& Tobias (1998, p. 66), "Clearly, those who accurately distinguish between what they have already mastered and what is yet to be learned have an advantage in these situations, since they can be more strategic and effective learners." However overall score estimates do not measure the degree to which students accurately distinguish between topics mastered and topics which still need work. To measure this we need to measure student calibrations of given topics, not the overall exam.

Some work of this nature has been carried out in the area of vocabulary and comprehension tests in English. (Everson \& Tobias, 1998; Lin, Moore, \& Zabrucky, 2001). Although they did find that better students calibrated more effectively, they also discovered that this differed with different populations of students. Further a vocabulary test is somewhat different than a problems solving practical exam and it is unclear to what degree such results may generalize to very different kinds of tests. In addition other researchers have found differences in calibration abilities of students in different subjects. (Everson, \& Tobias, 1998).

Ackerman, Beier, and Bowen (2002) found that calibration accuracy with the same population of college graduates from a variety of majors differs depending on subject domain: Social Science students accurately calibrated across many domains while business students systematically overestimated their performance.

The present research will investigate the degree to which students of IT can calibrate individual topic areas on specific tests and how these abilities relate to their overall performance in the course.

Most research on student calibration simply compares correlations. Correlation alone, however, does not fully represent accuracy of self-estimates, as Kruger and Dunning (1999, p.100) point out. They also suggest (p. 299), "Another measure of calibration that is sometimes used examines the mean of the absolute magnitude of the difference between estimates and criterion scores, what we call estimation error".

The present research will use a similar approach by simply recording the number of accurate student predictions on a number of topics and producing a \% correct figure for each student. Figures are compiled in this way because it is precisely correct calibrations of specific topics that should enable a student to focus on areas requiring further study.

For the purpose of the experiment very good students are those who score $85 \%$ or more on their midterm progress mark composed of a midterm exam, homework assignments and some tests including the one on which they are predicting their performance. Average and poor students are defined as those who score less than $85 \%$ on the midterm mark 


\section{Objectives of the Research}

To investigate the relationship between overall performance and calibration of specific topics in IT tests.

\section{Hypothesis}

Students scoring $85 \%$ or more on their midterm mark will correctly predict performance on specific topics in an Excel test significantly more often than students scoring less than $85 \%$ on their midterm mark.

For the purpose of this experiment a correct prediction is considered to be within $5 \%$ of the actual result obtained.

The author has chosen to compare good students with average as well as poor because it has been his observation that many good students take care to be sure of their knowledge on given topics,. an effort that he has not observed in average or poor students.

\section{Research Design}

Two groups of students were involved in the research. One group of 23 students, studying introductory MS Excel were given a pretest questionnaire in which they were asked to predict their performance on each topic on the upcoming test In their following class they were tested.

Another group of 30 students studying Advanced Excel functions were given two tests each preceded by a similar questionnaire in which they were asked to predict their performance in each topic area.

\section{Methodology}

These pre-test questionnaires were in the form of check boxes for each letter grade as illustrated by this example:

When you are tested on each of the following topics in Intermediate Excel indicate how well you expect to score.

Vlookup

\begin{tabular}{|c|c|c|c|c|c|c|c|c|c|}
\hline A & & B & & C & & D & & F less & \\
$90+$ & & $80-89$ & & $70-79$ & & $60-69$ & & than 60 & \\
\hline
\end{tabular}

Math functions

\begin{tabular}{|c|c|c|l|c|l|c|c|c|c|}
\hline $\mathrm{A}$ & & $\mathrm{B}$ & & $\mathrm{C}$ & & $\mathrm{D}$ & & $\begin{array}{c}\text { F less } \\
\text { than } 60\end{array}$ & \\
$90+$ & & $80-89$ & & $70-79$ & & $60-69$ & & than & \\
\hline
\end{tabular}

The predictions were converted to mid-point scores, for example, if a student checked the box to the right of B80-89 this was entered as 85\%. After the test was administered each topic in the marking scheme received a mark on 10 which was then converted to a mark on 100 . The absolute difference between the predicted score on each topic and the actual score was calculated. A difference of 5\% or less was considered an accurate prediction. The percentage of correct guesses for each student on each test was recorded. These percentages were used in the data analysis. 


\section{Results of this Experiment}

Table 1 shows the average percentage of correct prediction for students on each test in the study. Using Excel's single tailed ttest for groups of unequal variance we obtain the following measures of significance.

TABLE 1 The $\%$ of correctly calibrated items by Good students (B+ and above and by Average and Poor (below 85\%)

Single tailed ttest results for all tests.

\begin{tabular}{lccc}
\hline Test & B+ and above & Below 85\% & Significance \\
\hline Basic Excel (23 scores) & $\mathbf{7 4 \%}$ & $\mathbf{4 8 \%}$ & $<.01$ \\
\hline $\begin{array}{l}\text { Advanced XL test1 (30 } \\
\text { scores) }\end{array}$ & $\mathbf{5 8 \%}$ & $\mathbf{1 7 \%}$ & $<.001$ \\
\hline $\begin{array}{l}\text { Advanced XL test2 } \\
(30 \text { scores) }\end{array}$ & $\mathbf{3 6 \%}$ & $\mathbf{2 0 \%}$ & $\begin{array}{c}<.06 \text { not sig- } \\
\text { nificant }\end{array}$ \\
\hline & $\mathbf{5 3 \%}$ & $\mathbf{2 6 \%}$ & $<.0001$ \\
\hline $\begin{array}{l}\text { All tests all students (83 } \\
\text { scores) }\end{array}$ & & & \\
\hline
\end{tabular}

All test groups achieved significance except for the Advanced XL test 2 which narrowly missed significance at the .05 level. This test covered the most difficult material of the three. Previous research suggests that calibration in more complex material is more difficult (Lin \& Zabrucky, 1998) so it is possible that this was a factor. A small sample size for this test, only 30 test scores, however makes the result less conclusive.

Proof of the hypothesis being tested depends on the complete measure of all tests and all students, a total of 83 test scores. This achieved significance beyond the .0001 level.

\section{Conclusions}

Very good students writing IT tests do calibrate individual topics significantly better than average or poor students.

\section{Implications for Further Research}

Numerous studies indicate that practice and feedback in calibration do not significantly improve student calibration (Bol et al, 2005). However again, students are not asked to calibrate performance on specific topics. Calibrating an overall score may not be seen as a very important or useful skill. It would be interesting to see if practice of calibration on specific topics would improve student calibration on specific topics. If so it might lead to improved results as calibration improves.

\section{References}

Ackerman, P. L., Beier, M. E., \& Bowen, K. R. (2002). What we really know about our abilities and our knowledge. Personality and Individual Differences, 33,587-605.

Baker, L. (1989). Metacognition, comprehension monitoring, and the adult reader. Educational Psychology Review, 1,3-38. 
Bol, L., Hacker, D., \& Allen, P. (2005). The influence of overt practice, achievement level, and explanatory style on calibration accuracy and performance. Journal of Experimental Education, 73(4), 269-290.

Brown, A. L. (1980). Metacognitive development and reading. In R. J. Siro, B. B. Bruce, \& W. F. Brewer (Eds.), Theoretical issues in reading comprehension (pp. 453-481). Hillsdale, NJ: Erlbaujm Associates.

Brown, A. L., \& Campione, J. C. (1986). Psychological theory and the study of learning disabilities. American Psychologist, 14,1059-1068.

Everson, H., \& Tobias, S. (1998). The ability to estimate knowledge and performance in college: A metacognitive analysis. Instructional Science, 26, 65-79.

Garner, R., \& Alexander, P. (1989). Metacognition: Answered and unanswered questions. Educational Psychologist, 24, 143-158.

Glenberg, A. M., Snocki, T., Epstein, W., \& Morris, C. (1987). Enhanced calibration of comprehension. Journal of Experimental Psychology: General, 116, 119-136.

Horgan, D. (1990). Students' predictions of test grades: Calibration and metacognition. Paper presented at the Annual Meeting of the American Educational Research Association, Boston, MA, April 16-20, 1990.

Kruger, J., \& Dunning, D. (1999). Unskilled and unaware of it: How difficulties in recognizing one's own incompetence lead to inflated self-assessments. Journal of Personality and Social Psychology, 77(2), 221-232.

Lin, L-M., Moore, D., \& Zabrucky, K. M. (2001). An assessment of students' calibration of comprehension and calibration of performance using multiple measures. Reading Psychology, 2, 111-128.

Lin, L. \& Zabrucky, K.M. (1998) Calibration of comprehension: Research and implications for education and instruction. Contemporary Educational Psychology, 23(4), 345-391.

Maki, R., \& Serra, M. (1992). Role of practice tests in the accuracy of test predictions on text material. Journal of Educational Psychology, 84(2), 200-210.

Nietfeld, J. L., \& Schraw, G. (2002). The effect of knowledge and strategy training on monitoring accuracy. The Journal of Educational Research, 95,131-142.

Schraw, G., Potenza, M. T., \& Nebelsick-Gullet, L. (1993). Constraints on the calibration of performance. Contemporary Educational Psychology, 18, 455-463.

Tenenberg, J., \& Murphy, L. (2005). Knowing what I know: An investigation of undergraduate knowledge and self-knowledge of data structures. Computer Science Education, 15(4).297-315.

\section{Biography}

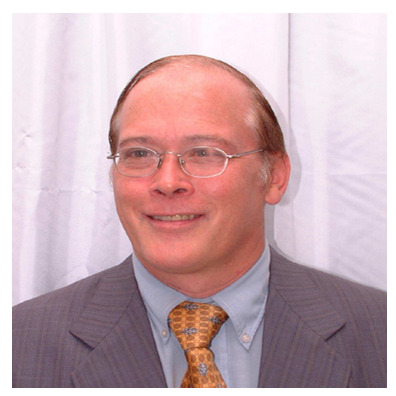

D. Neil Westley has been teaching programming and IT for over 25 years at college and university level and has authored a recent text book on MS Excel: Intermediate Excel for Foreign Language Students.

His research initiatives in teaching methodologies for IT and computing reflect his keen interest in learning processes as applied to these disciplines. He is currently a resident of the United Arab Emirates on faculty at the Petroleum Institute 